\title{
Marine biodiversity and ecosystem functioning: what's known and what's next?
}

\author{
L Gamfeldt
}

JS Lefcheck

Virginia Institute of Marine Science

JEK Byrnes

BJ Cardinale

JE Duffy

Follow this and additional works at: https://scholarworks.wm.edu/vimsarticles

Part of the Aquaculture and Fisheries Commons

\section{Recommended Citation}

Gamfeldt, L; Lefcheck, JS; Byrnes, JEK; Cardinale, BJ; and Duffy, JE, Marine biodiversity and ecosystem functioning: what's known and what's next? (2015). Oikos, 124(3), 252-265.

10.1111/oik.01549

This Article is brought to you for free and open access by the Virginia Institute of Marine Science at W\&M ScholarWorks. It has been accepted for inclusion in VIMS Articles by an authorized administrator of W\&M ScholarWorks. For more information, please contact scholarworks@wm.edu. 


\title{
Marine biodiversity and ecosystem functioning: what's known and what's next?
}

\author{
Lars Gamfeldt, Jonathan S. Lefcheck, Jarrett E. K. Byrnes, Bradley J. Cardinale, J. Emmett Duffy and \\ John N. Griffin
}

L. Gamfeldt (lars.gamfeldt@gu.se), Dept of Biological and Environmental Sciences, Univ. of Gothenburg, Box 461, SE-40530 Gothenburg, Sweden. - J. S. Lefcheck, Dept of Biological Sciences, Virginia Inst. of Marine Science, The College of William and Mary, PO Box 1346, Rt 1208 Greate Rd, Gloucester Point, VA 23062-1346, USA. - J. E. K. Byrnes (<orcid.org/0000-0002-9791-9472>), Dept of Biology, Univ. of Massachusetts Boston, 100 Morrissey Blvd., Boston, MA 20125, USA. - B. J. Cardinale, School of Natural Resources and Environment, Univ. of Michigan, Ann Arbor, MI 48109, USA. - J. E. Duffy, Tennenbaum Marine Observatories Network, Smithsonian Inst., Washington, WA 20013-7012, USA. - J. N. Griffin, Dept of Biosciences, Wallace Building, Swansea Univ., Singleton Park, Swansea, SA2 8PP, UK.

\begin{abstract}
Marine ecosystems are experiencing rapid and pervasive changes in biodiversity and species composition. Understanding the ecosystem consequences of these changes is critical to effectively managing these systems. Over the last several years, numerous experimental manipulations of species richness have been performed, yet existing quantitative syntheses have focused on a just a subset of processes measured in experiments and, as such, have not summarized the full data available from marine systems. Here, we present the results of a meta-analysis of 110 marine experiments from 42 studies that manipulated the species richness of organisms across a range of taxa and trophic levels and analysed the consequences for various ecosystem processes (categorised as production, consumption or biogeochemical fluxes).

Our results show that, generally, mixtures of species tend to enhance levels of ecosystem function relative to the average component species in monoculture, but have no effect or a negative effect on functioning relative to the "highestperforming' species. These results are largely consistent with those from other syntheses, and extend conclusions to ecological functions that are commonly measured in the marine realm (e.g. nutrient release from sediment bioturbation). For experiments that manipulated three or more levels of richness, we attempted to discern the functional form of the biodiversity-ecosystem functioning relationship. We found that, for response variables related to consumption, a powerfunction best described the relationship, which is also consistent with previous findings. However, we identified a linear relationship between richness and production. Combined, our results suggest that changes in the number of species will, on average, tend to alter the functioning of marine ecosystems. We outline several research frontiers that will allow us to more fully understand how, why, and when diversity may drive the functioning of marine ecosystems.
\end{abstract}

\footnotetext{
The oceans host an incredible number and variety of species. However, human activities are driving rapid $\frac{n}{0}$ changes in the marine environment. It is imperative we understand ecosystem consequences of any associated \& loss of species. We summarized data from 110 experiments that manipulated species diversity and evaluated resulting changes to a range of ecosystem responses. We show that losing species, on average, decreases producके tivity, growth, and a myriad of other processes related to how marine organisms capture and utilize resources. Finally, we suggest that the loss of species may have stronger consequences for some processes than others.
}

In the current era of global change, marine systems are heavily impacted by human activities including overexploitation, eutrophication, pollution and species introductions (Halpern et al. 2008, Hoegh-Guldberg and Bruno 2010, Burrows et al. 2011), and face unique threats such as ocean acidification (Doney et al. 2012). One consequence of these stressors is a documented change in species composition and richness (Jones et al. 1994, Sax and Gaines 2003, Dulvy et al. 2003, Byrnes et al. 2007, Hawkins et al. 2009, Beaugrand et al. 2010). Given that marine systems worldwide provide a variety of valuable ecosystem services (MEA 2005, Barbier et al. 2010), and previous evidence suggest these services can be linked to changes in biodiversity (Cardinale et al. 2012, Balvanera et al. 2014), it is crucial to understand the consequences of biodiversity loss in the world's oceans.

Since the publication of the first experiments studying the effects of changes in biodiversity on ecosystem functioning in the early 1990s (Naeem et al. 1994, Tilman and Downing 1994), consensus is now emerging that declines in biodiversity have negative consequences for ecosystem functions such as production, resource use efficiency, and nutrient cycling (Loreau et al. 2001, Hooper et al. 2005, Balvanera et al. 
2006, Naeem et al. 2009a, Schmid et al. 2009, Cardinale et al. 2012). Early reviews of biodiversityecosystem functioning noted that the marine realm was underrepresented (Emmerson and Huxham 2002, Hooper et al. 2005), but significant progress has been made and the number of manipulative studies in marine systems has increased rapidly over the past few years (Worm et al. 2006, Stachowicz et al. 2007, Cardinale et al. 2011, Solan et al. 2012, O'Connor and Byrnes 2013).

Indeed, marine studies have been instrumental in shifting the focus towards higher trophic levels, specifically looking at herbivory and predation (Duffy 2002, Duffy et al. 2003, Bruno and O'Connor 2005, O'Connor and Crowe 2005, Stachowicz et al. 2007, Gamfeldt and Hillebrand 2008), and how these interact across multiple trophic levels (Gamfeldt et al. 2005, Bruno et al. 2008, Douglass et al. 2008). Marine studies contributed substantially to our understanding of the role of predator diversity (Byrnes et al. 2006, Griffen 2006, Griffin et al. 2008, O'Connor et al. 2008, O'Connor and Bruno 2009, Griffin and Silliman 2011), and have helped elucidate the role of random vs. ordered scenarios of species loss (Solan et al. 2004, Bracken et al. 2008, Bracken and Low 2012). They have also investigated how biodiversity influences ecosystem processes that are generated non-trophically by ecosystem engineers (e.g. nutrient fluxes from bioturbation in soft-benthos) (Emmerson et al. 2001, Solan et al. 2004), used controlled experiments to further our understanding about the relative roles of species density, identity and diversity (O'Connor and Crowe 2005, Benedetti-Cecchi 2006, Griffin et al. 2008, Byrnes and Stachowicz 2009a), and explored how connectivity among communities alters such relationships (France and Duffy 2006, Matthiessen et al. 2007).

Worm and colleagues (Worm et al. 2006) provided the first quantitative meta-analysis of 32 marine experimental manipulations of either species or genetic richness, finding generally positive effects of diversity of either producers or consumers as compared to average monocultures for a wide variety of ecosystem functions. Following this, Stachowicz et al. (2007) published a more extensive review of 52 papers that manipulated the richness of not just species, but also functional groups or genotypes, in the marine realm. In total, those papers reported a significant effect of richness for about $70 \%$ of the experiments. The review by Stachowicz et al. (2007), however, did not quantify the size of the diversity effect. Rather, they simply tallied the studies that reported a significant relationship between richness and functioning in marine experiments.

In this paper, we provide an extensive quantitative summary of the current state of knowledge in marine biodiversity-ecosystem functioning research. We provide a rigorous meta-analysis of 110 marine experiments that manipulated the species richness and analysed some ecosystem response. We employ a mixed modelling framework to specifically test how changes in species richness affect a range of functions in different marine systems. We also provide the first estimates of the functional form (e.g. linear, logarithmic, etc.) of the relationship between species richness and ecosystem responses in marine systems. Finally, we discuss shortcomings of the current literature and suggest fruitful future research topics.

\section{Methods}

\section{The data}

To quantify the effects of changes in species richness on biomass production, consumption, and biogeochemical fluxes, we assembled a dataset of 42 studies that performed 110 experimental manipulations of species richness from 1999 to May 2011. For inclusion, studies must have manipulated the richness of $\geq 3$ species, included treatments with all species together and each species alone, and used a substitutive design. A substitutive design means that total initial biomass (or response variable of choice) is held constant across richness levels, and is the most commonly employed design in biodiversity-ecosystem functioning research.

We began by extracting all marine studies from an existing, publicly available database used in previous metaanalyses of biodiversity effects (Cardinale et al. 2009, 2011). These syntheses focused solely on studies that examined how richness influenced resource capture and/or the production of biomass. They did not include many of the processes that are of interest in marine studies (e.g. bioturbation), therefore we supplemented the existing database in several ways. First, we added any studies reviewed in Stachowicz et al. (2007) that met our criteria for inclusion. Second, we searched ISI Web of Science using two search strings. 1) '(biodiversity OR diversity OR richness) AND function* AND marine', and 2) 'biodiversity AND function* AND marine'. This resulted in the addition of nine more studies that were not included in Cardinale et al. (2009), Cardinale et al. (2011) and Stachowicz et al. (2007). Table 1 lists all the studies and the number of experiments included in each study analyzed in this meta-analysis.

We categorized each experiment according to type of response variable (production, consumption, biogeochemical fluxes), study system (hard substrate, soft substrate, seagrass, pelagic, salt marsh), and focal trophic group (primary producers, herbivores, carnivores, mixed diet) (see Table 2 for an overview). We also categorized experiments based on whether the response variable was measured at the focal trophic group itself (i.e. producers, herbivores, carnivores, mixed feeders), at the level of their resources, or at the next trophic level up in the food web.

Biogeochemical fluxes have been a central focus in marine experiments that studied the effects of animal species richness on soft substrates (Raffaelli et al. 2003, Ieno et al. 2006, Norling et al. 2007), but the results have not been summarised prior to the present analysis. Examples of the different response variables are provided in Table 2. The geographical distribution of the studies is shown in Fig. 1, and the number of studies and experiments for each study system and focal trophic group are presented in Fig. 2.

Twenty-seven percent of the studies included in this meta-analysis used rates of ecological processes (e.g. the rate of oxygen production, rate of biomass production, or rate of resource depletion) as response variables. The remaining studies analyzed state variables (e.g. the standing stock biomass, volume or cover). These state variables have often been used as proxies for rates of ecological processes in the biodiversity-functioning literature. For example, the standing stock biomass of primary producers at the peak of the 
Table 1. A list of the 42 studies included in the analyses, their study system, and the number of unique experiments within each study.

\begin{tabular}{llc}
\hline Paper & \multicolumn{1}{c}{ System } & $\begin{array}{c}\text { No. of } \\
\text { experiments }\end{array}$ \\
\hline Blake and Duffy 2010 & seagrass & 4 \\
Boyer et al. 2009 & hard substrate & 8 \\
Bracken et al. 2008 & hard substrate & 16 \\
Bracken and Stachowicz 2006 & hard substrate & 1 \\
Bruno et al. 2005 & hard substrate & 5 \\
Bruno and O'Connor 2005 & hard substrate & 1 \\
Bruno et al. 2006 & hard substrate & 2 \\
Bruno et al. 2008 & hard substrate & 4 \\
Byrnes et al. 2006 & hard substrate & 1 \\
Byrnes and Stachowicz 2009a & hard substrate & 1 \\
Byrnes and Stachowicz 2009b & hard substrate & 2 \\
Callaway et al. 2003 & salt marsh & 1 \\
Dam and Lopes 2003 & pelagic & 2 \\
Douglass et al. 2008 & hard substrate & 10 \\
Duffy et al. 2001 & seagrass & 1 \\
Duffy et al. 2003 & seagrass & 1 \\
Duffy et al. 2005 & seagrass & 2 \\
Ericson et al. 2009 & hard substrate & 2 \\
Foster et al. 1999 & hard substrate & 2 \\
Gamfeldt et al. 2005 & pelagic & 7 \\
Godbold et al. 2009 & soft substrate & 3 \\
Griffin et al. 2008 & hard substrate & 2 \\
Griffin et al. 2009 & hard substrate & 3 \\
Griffin et al. 2010 & hard substrate & 1 \\
Gustafsson and Boström 2009 & seagrass & 1 \\
Hillebrand et al. 2009 & hard substrate & 2 \\
leno et al. 2006 & soft substrate & 1 \\
Jaschinski et al. 2009 & seagrass & 2 \\
Karlson et al. 2010 & soft substrate & 1 \\
Karlson et al. 2011 & soft substrate & 1 \\
Matthiessen et al. 2007 & hard substrate & 2 \\
Mermillod-Blondin et al. 2005 & soft substrate & 1 \\
Moore and Fairweather 2006 & seagrass & 1 \\
Moorthi et al. 2008 & soft substrate & 6 \\
Murray and Marcus 2002 & pelagic & 2 \\
Norling et al. 2007 & soft substrate & 1 \\
O'Connor and Bruno 2009 & hard substrate & 2 \\
O'Connor et al. 2008 & hard substrate & 1 \\
Vanelstandicz et al. 2008a & 1 \\
\hline St. 2008b & seagrass & 1 \\
\hline
\end{tabular}

growing season or at the end of an experiment has been analyzed and discussed as a proxy for the rate of production of biomass (Tilman et al. 1997). Since previous analyses have shown that rate- and state variables may respond differently to changes in biodiversity (Schmid et al. 2009), we also categorized the response variable as either rates or states.

\section{Statistical analyses: log response ratios}

From each experiment, we extracted the mean value of the response variable, its variance (standard deviation), and the sample size for each response at each level of richness. We also identified the single species with the most extreme performance, i.e. highest or lowest function value (depending on whether a higher or lower response was predicted to be optimal from theory), and recorded the mean value of functioning, variance in functioning, and sample size for that species by itself. This information allowed us to construct two common indices based on the log response ratio (LR, Hedges et al. 1999). The first, $L_{\text {net }}$, is defined as the proportional difference in the response variable $Y$ between the average value of the most species-rich polyculture $\left(\mathrm{Y}_{\mathrm{Smax}_{\max }}\right)$ and the average value of these same species grown in monoculture $\left(\mathrm{Y}_{\text {AveMono }}\right)$ :

$$
L R_{\text {net }}=\ln \left(\frac{Y_{\text {Smax }}}{Y_{\text {AveMono }}}\right)
$$

An $\mathrm{LR}_{\text {net }}>0$ indicates that function in the diverse mixture is greater than the average species when grown alone. The second, $\mathrm{LR}_{\mathrm{ext}}$, is:

$$
L R_{\text {ext }}=\ln \left(\frac{Y_{\text {Smax }}}{Y_{\text {ExtMono }}}\right)
$$

where $Y_{S \max }$ is the response variable in the most diverse polyculture in an experiment and $\mathrm{Y}_{\text {ExtMono }}$ is the value of the most extreme monoculture. An $\mathrm{LR}_{\text {ext }}>0$ indicates that function in the diverse mixture is greater than function for the single most extreme species when alone.

For each response, we specified the expected direction of the diversity effect, i.e. whether the function was predicted to be maximized or minimized with increasing richness.

Table 2. A description of the different response variables included in each main category of function (production, consumption, biogeo-

\begin{tabular}{|c|c|c|}
\hline Function category & Functions & Units \\
\hline Production & $\begin{array}{l}\text { - biomass/volume/abundance/cover/size } \\
\text { - chlorophyll a } \\
\text { - production of offspring or eggs } \\
\text { - survival } \\
\text { - hatching success } \\
\text { - abundance of epifauna }\end{array}$ & $\begin{array}{l}\text { weight volume }{ }^{-1} \text { (e.g. g } \mathrm{I}^{-1} \text {, no. volume } \mathrm{v}^{-1}, \mathrm{O}_{2} \text { time }^{-1} \text {, } \\
\text { weight (e.g. g), weight area }{ }^{-2} \text {, cover area }{ }^{-2} \text {, shoots } \\
\text { per plot, length (e.g. mm), numbers pair }{ }^{-1} \text { (brood } \\
\text { production or eggs), \% (survival, gonad index, hatching } \\
\text { success), weight time }{ }^{-1} \text {, no. of eggs time }{ }^{-1}\end{array}$ \\
\hline Consumption & $\begin{array}{l}\text { - biomass/volume/abundance/ } \\
\text { - cover of resource or prey } \\
\text { - nutrient uptake/incorporation } \\
\text { - ingestion rate }\end{array}$ & $\begin{array}{l}\text { weight volume }{ }^{-1} \text { (e.g. } \mathrm{g} \mathrm{I}^{-1} \text { ), number volume }{ }^{-1} \text {, number/ } \\
\text { cover/weight/volume area } \mathrm{a}^{-2}, \mathrm{I} \mathrm{g}^{-1} \mathrm{~h}^{-1} \text {, proportional } \\
\text { change, weight, } \mathrm{mg} \mathrm{g}^{-1} \text {, concentration (e.g. molar), } \\
\text { weight time } \mathrm{e}^{-1}\end{array}$ \\
\hline $\begin{array}{l}\text { Biogeochemical } \\
\text { fluxes }\end{array}$ & $\begin{array}{l}\text { - water exchange } \\
\text { - fluxes of nutrients } \\
\text { - fecal production } \\
\text { - oxygen flux and oxidized sediments }\end{array}$ & $\begin{array}{l}\text { volume, concentration, concentration area }{ }^{-2} \text { time }^{-1} \text {, } \\
\text { number } \text { area }^{-2} \text { time }^{-1} \text {, number time } \\
\text { layer })\end{array}$ \\
\hline
\end{tabular}
chemical fluxes), and their units. Some variables have been measured as both state and rate variables. 


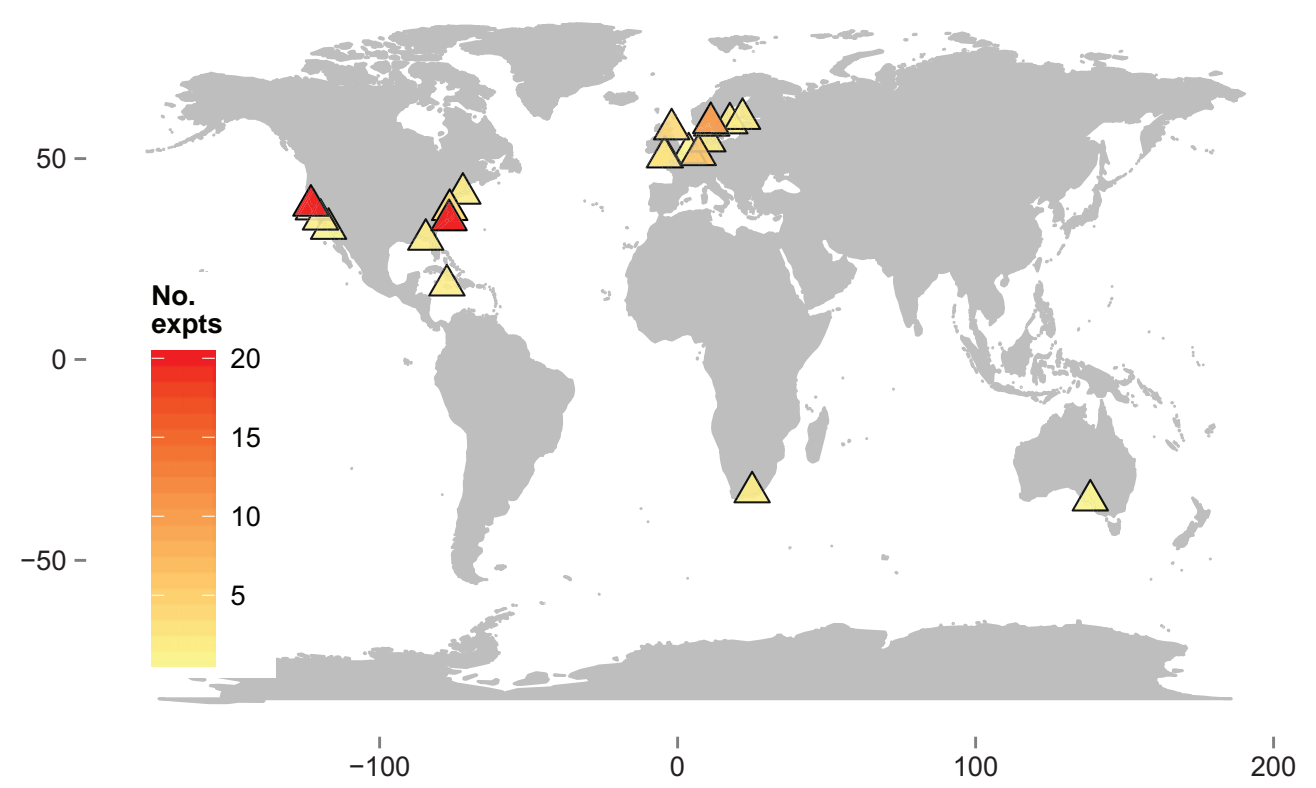

Figure 1. A global map showing the location of the experiments included in this meta-analysis.

Wherever possible, we relied on the predictions set forth by the authors of the original publication, or those suggested by ecological theory. For example, the expected effect of changes in diversity within a focal trophic level on processes within that same focal group is often expected to be positive (e.g. changes in diversity of plants enhances the standing stock biomass of plants, Loreau 1998). Similarly, the expected effect of diversity on the standing stock of the trophic level below the one that is being manipulated is expected to be negative (e.g. diversity enhances resource depletion, Thébault and Loreau 2003, Ives et al. 2005, Duffy et al. 2007).

However, there are a multitude of predictions for bottom-up effects of diversity, i.e. the effect of diversity on

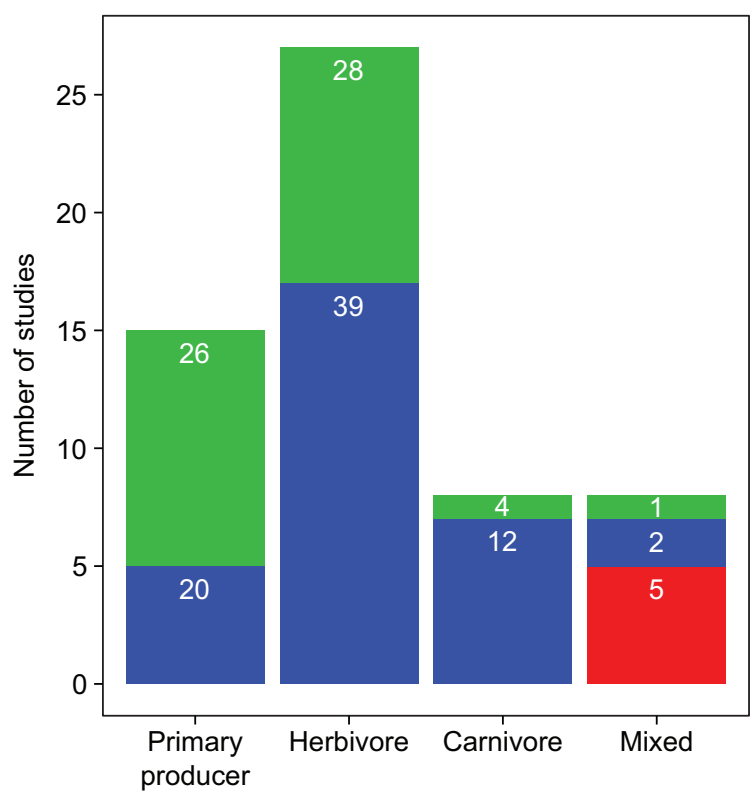

Focal trophic group the trophic level above the one that is being manipulated. One possibility is that consumer production may respond positively to increased prey diversity because the diverse prey assemblage contains more and varied nutrients (the 'balanced diet' hypothesis); alternatively, consumer production might respond negatively to higher prey diversity if diverse prey assemblages have enhanced prey defenses (Duffy et al. 2007). We identified two experiments testing bottomup effects of diversity, and for which the predicted direction of a diversity effect might be conflicted. The first (Gustafsson and Boström 2009) hypothesized a positive effect of seagrass richness on the amount of epifauna because increasing diversity can increase seagrass structural habitat. The second

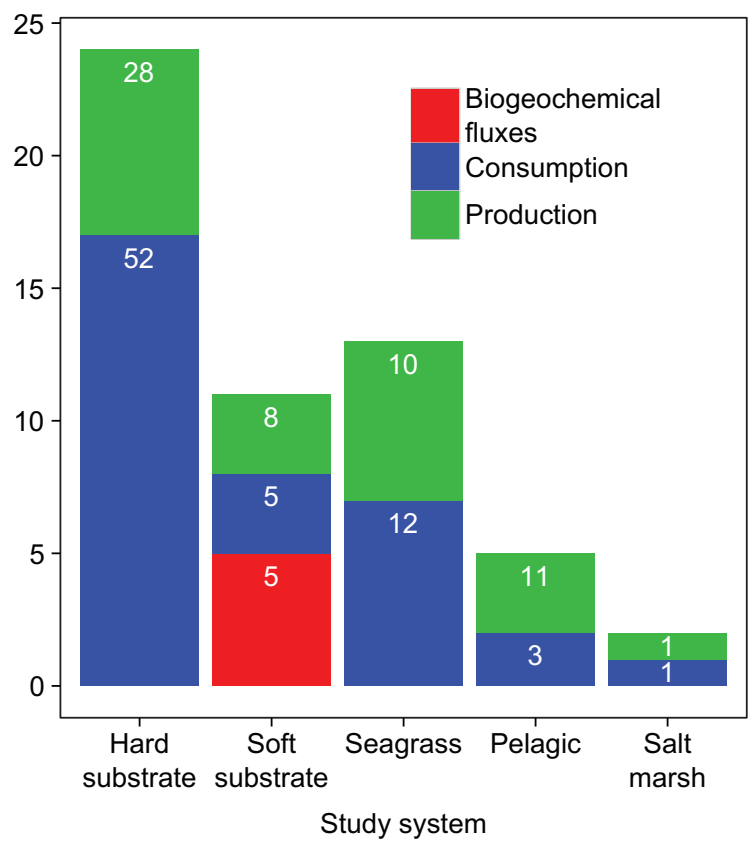

Figure 2. The number of studies and experiments for each function category (production, consumption, biogeochemical fluxes), trophic group (primary producer, herbivore, carnivore, mixed diet), and system (hard substrate, soft substrate, seagrass, pelagic, salt marsh). 
study (Gamfeldt et al. 2005) tested the effect of algal prey richness on herbivore biomass. Since all prey species were edible the authors hypothesized that the direction of a richness effect should be positive. Both these experiments were thus retained in our analyses.

We removed any experiments that measured effects exceeding $>1$ trophic level away from the focal organisms whose diversity was manipulated (as some experiments in the Bruno and O'Connor 2005 and Blake and Duffy 2010 studies). When the expected direction was negative, e.g. the response was expected to be minimized with increasing diversity, then we simply inverted the ratio: $1 / \mathrm{LR}_{\mathrm{ext}}$. For papers that included multiple sampling points over time, we used only data from the last sampling point (Poore et al. 2012), as this is least likely to be influenced by transient responses. When there were orthogonal experimental treatments (e.g. top predator present or absent), each level of the factors was considered an independent experiment.

To investigate the overall effect of species richness, we calculated a mean log response ratio for both $\mathrm{LR}_{\text {net }}$ and $\mathrm{LR}_{\mathrm{ext}}$, which was simply the unweighted average of the constituent $\log$ ratios. The variance of this statistic was the sample variance of the log ratios, which we used to construct $95 \%$ confidence intervals. We considered any mean log response ratio whose $95 \%$ CIs did not overlap zero to be significantly different from zero (either positively or negatively). We also calculated both variance- and sample size-weighted log response ratios for each study following Hedges et al. (1999), using the experiment standard deviations and sample sizes collected from the original publications. However, the inferences from these two weighted analyses were no different from the unweighted analysis (see code in Supplementary material). Therefore, we chose to present the unweighted analysis here, as it prevents more controlled studies (i.e. those conducted in the lab or in micro/mesocosms versus those conducted in the field) from exerting an inordinate influence on the mean $\log$ ratios (as in Cardinale et al. 2006, 2011, Griffin et al. 2013). We further parsed the mean log ratios by trophic level, habitat, trophic direction, and response type (state versus rate variables) and identified significant differences based on $95 \%$ CIs, as above. The definition of a rate variable is one that is reported as per unit time or proportional change.

\section{Statistical analyses: curve-fitting}

In addition to the analyses using log response ratios, we also analyzed the form of the relationship that best describes the effect of richness on functioning. For this purpose we used the 27 studies and 66 experiments in our database that manipulated three or more richness levels. We extracted the mean level of functioning at each level of richness $\left(\mathrm{Y}_{S}\right)$ relative to the average monoculture $\left(\mathrm{Y}_{\text {AveMono }}\right)$ : $\mathrm{Y}_{\mathrm{S}} / \mathrm{Y}_{\text {AveMono }}$ (sensu Cardinale et al. 2006), or the proportional change in functioning with each successive level of richness relative to the single-species treatments. We then regressed this response against richness in a non-linear mixed effects framework, allowing the slope and intercept of the richness effect to vary by study. Including study as a random effect allowed us to account for the variation due to an experiment being in a particular study when estimating the overall effect of richness on the response. We fitted our data using the following relationships: linear, logarithmic, power, and saturating

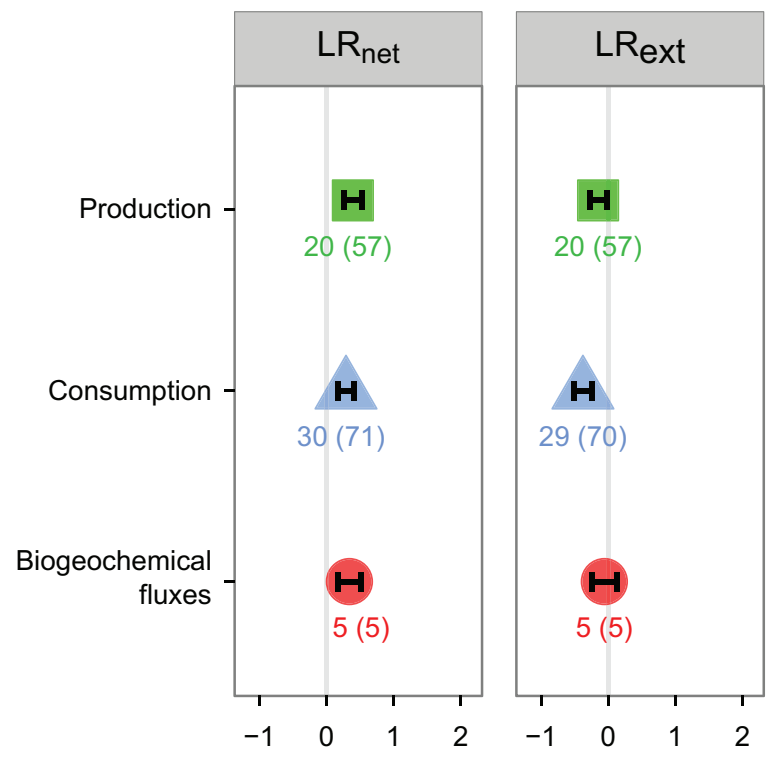

Figure 3. The log response ratios $\mathrm{LR}_{\text {net }}$ and $\mathrm{LR}_{\text {ext }}$ grouped by the three function categories: production, consumption and biogeochemical fluxes. The horizontal lines represent 95\% confidence intervals.

(Michaelis-Menten), as well as a null model including only the random factor (see R code in Supplementary material Appendix 1 and Cardinale et al. 2011). Akaike weights were used to identify the most parsimonious model(s) for each response variable (Burnham and Anderson 2002).

We used the coefficients from the most parsimonious models to predict the overall effect of richness on each of the three different function categories (production, consumption, biogeochemical fluxes). We then randomly sampled our data and bootstrapped the model 999 times to arrive at an approximate $95 \%$ confidence band for the overall fit. This approach improves on previous efforts to categorize the shape of diversity-function relationships (Cardinale et al. 2006, 2011) which fitted a separate set of curves to each individual experiment, and then used vote-counting based on the type of relationship with the lowest AIC value for each experiment. All analyses were done in $\mathrm{R}$ (ver. 3.0.2) using the package nlme (Pinheiro et al. 2013). All R code is available in Supplementary material Appendix 1, and the data in Supplementary material Appendix 2.

\section{Results}

\section{General effects of species richness}

Across all marine systems and trophic groups, the most species-rich polyculture had higher levels of production, higher consumption, and higher biogeochemical fluxes than the average monoculture $\left(\mathrm{LR}_{\mathrm{net}}\right.$ was significantly positive for all three function categories based on $95 \%$ confidence intervals, Fig. 3). However, when compared to the monoculture with the most extreme value $\left(\mathrm{LR}_{\mathrm{ext}}\right)$, polycultures show significantly lower levels of production and consumption, and similar levels for biogeochemical fluxes (Fig. 3).

Looking at experiments based on whether the response variable was measured at the focal or adjacent trophic level does little 


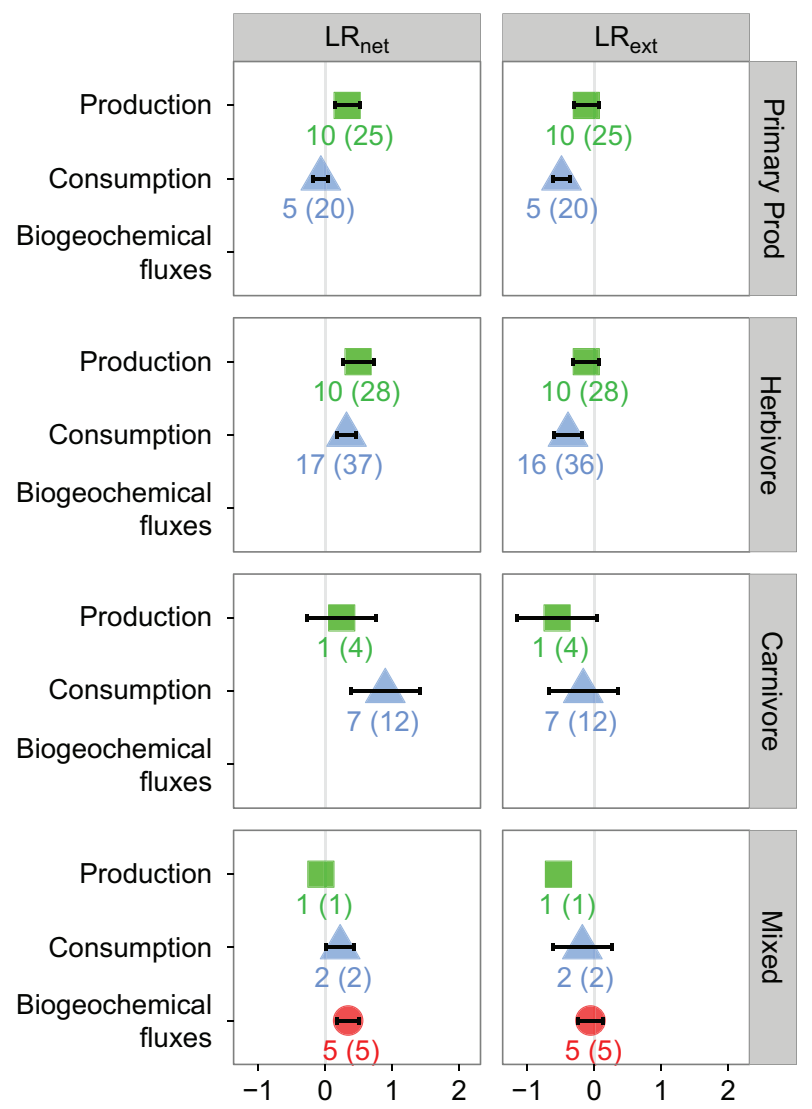

Figure 4. The log response ratios $\mathrm{LR}_{\text {net }}$ and $\mathrm{LR}_{\text {ext }}$ grouped by function category and trophic group. The horizontal lines represent 95\% confidence intervals.

to change this general picture. Only two studies looked at bottom-up effects of producer richness on consumer production, which is not different from zero, though we have little power to estimate that response ratio (Supplementary material Appendix 3, Fig. A1). For consumption, the response ratio is positive when we analyse the effects at the level of the resources (e.g. the effect of algal richness on nutrients in the water column). When we look at effects at the level of the focal trophic level (e.g. the effect of algal richness on algal biomass) the confidence interval overlaps zero (Supplementary material Appendix 3 Fig. A1).

\section{Effects of species richness by trophic groups}

For production, $\mathrm{LR}_{\text {net }}$ was positive for both primary producers and herbivores (Fig. 4), reflecting the general trend (Fig. 3). Meanwhile, there was no effect of richness on production of either carnivores or mixed feeders, though the low sample sizes for these trophic groups were likely responsible (Fig. 4).

For consumption, $\mathrm{LR}_{\text {net }}$ was positive for herbivores, carnivores and mixed feeders, but not for primary producers 'consuming' inorganic resources (Fig. 4). It should be noted that the data for primary producers and consumption is constrained to 20 experiments from five studies, of which two studies (Bracken and Stachowicz 2006, Bracken et al. 2008) contributed 17 experiments. The results are thus strongly driven by these studies. However, detailed exploration of the

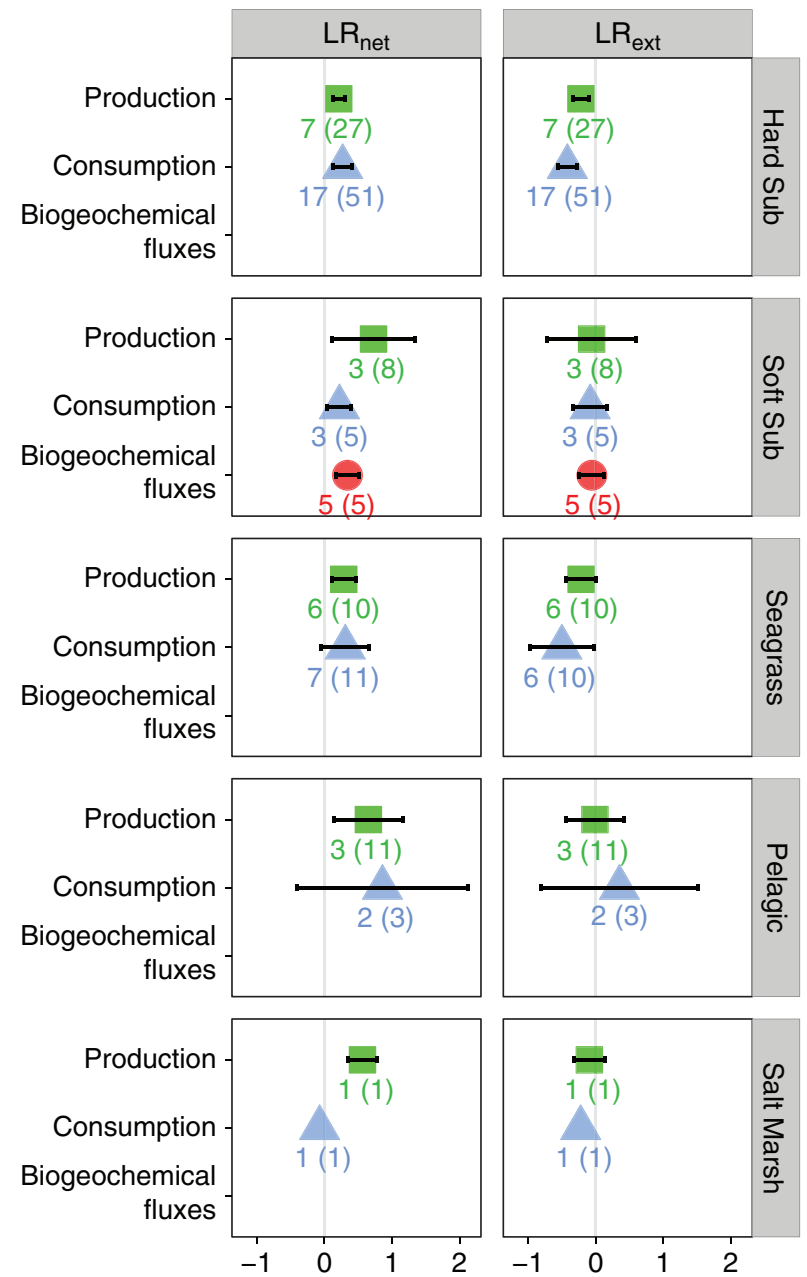

Figure 5. The log response ratios $\mathrm{LR}_{\text {net }}$ and $\mathrm{LR}_{\mathrm{ext}}$ grouped by function category and system. The horizontal lines represent $95 \%$ confidence intervals.

response ratios for these five studies shows that the removal of any of the five studies did not qualitatively change the result (Supplementary material Appendix 3 Fig. A2).

The pattern for $\mathrm{LR}_{\mathrm{ext}}$ differed from those found for $\mathrm{LR}_{\text {net }}$. For production, all trophic groups showed a marginally or non-significant trend in $\mathrm{LR}_{\mathrm{ext}}$. The most species-rich polyculture often had significantly lower functioning relative to the most extreme monoculture (Fig. 3). For consumption, the most species-rich polyculture performed more poorly than the most extreme monoculture (had a negative $\mathrm{LR}_{\text {ext }}$ ) for both primary producers and herbivores, but for both carnivores and mixed feeders $\mathrm{LR}_{\text {ext }}$ did not differ from zero (Fig. 4). Biogeochemical fluxes were in all cases mediated by organisms considered to belong to a mixed feeding group, and therefore effects shown in Fig. 4 (both $\mathrm{LR}_{\text {net }}$ and $\mathrm{LR}_{\text {ext }}$ ) reflected the same trends as seen in other groups; i.e. a positive $\mathrm{LR}_{\text {net }}$ and an $\mathrm{LR}_{\text {ext }}$ that did not differ from zero.

\section{Effects of species richness by system}

When results were parsed by type of marine system, we found consistent positive effects of richness on production across systems compared to the average monoculture $\left(\mathrm{LR}_{\text {net }}\right)$. 
Table 3. Results from AIC analyses for each function category and species richness-function curve relationship. Italics highlight the best-fitting models.

\begin{tabular}{lccc}
\hline Function category & AIC & AIC weight & Delta AIC \\
\hline Production & & & \\
$\quad$ Null & 266.2 & 0.00 & 45.8 \\
$\quad$ Linear & 220.4 & 0.93 & 0.0 \\
$\quad$ Logarithmic & 225.6 & 0.069 & 5.2 \\
$\quad$ Power & 239.8 & 0.00 & 19.4 \\
$\quad$ Saturating & 245.4 & 0.00 & 25.0 \\
Consumption & & & \\
$\quad$ Null & 304.4 & 0.00 & 182 \\
$\quad$ Linear & 144.5 & 0.00 & 22.3 \\
$\quad$ Logarithmic & 139.5 & 0.00 & 17.3 \\
$\quad$ Power & 122.2 & 1.00 & 0.0 \\
$\quad$ Saturating & 321.7 & 0.00 & 200 \\
Biogeochemical fluxes & & & \\
$\quad$ Null & 39.7 & 0.00 & 13.4 \\
$\quad$ Linear & 26.8 & 0.22 & 0.6 \\
$\quad$ Logarithmic & 26.3 & 0.30 & 0.0 \\
$\quad$ Power & 26.6 & 0.26 & 0.3 \\
$\quad$ Saturating & 26.7 & 0.23 & 0.5 \\
\hline
\end{tabular}

In contrast, there were positive effects on consumption only for hard and soft substrates (Fig. 5). However, we note that there were trends towards positive values of $\mathrm{LR}_{\text {net }}$ for consumption in both seagrass and pelagic systems, and that there were very low sample sizes across all three of the systems that are responsible for the wide confidence intervals on $\mathrm{LR}_{\text {net }}$. Both hard substrate and seagrass systems showed negative effects of richness compared to the best-performing monoculture $\left(\mathrm{LR}_{\text {ext }}\right)$, while $\mathrm{LR}_{\text {ext }}$ was indistinguishable from zero for both soft substrate and pelagic systems. We note again the generally lower sample size for these systems.

\section{State versus rate variables}

There was only one small difference between the state and rate log response variables (Supplementary material Appendix 3 Fig. A3). While biogeochemical fluxes were positive for $\mathrm{LR}_{\text {net }}$ overall (Fig. 3) their confidence interval overlapped zero for state variables (Supplementary material Appendix 3 Fig. A3). Note, however, the low sample size for the state variables, which was three experiments from three studies.

\section{Differences between types of experiments}

We found only small, mostly non-significant differences between experiments that were performed in the lab, in mesocosms, and in the field (Supplementary material Appendix 3 Fig. A4). This resonates with the findings in Godbold (2012), which also found only subtle differences in effect size between lab- and field experiments.

\section{Curve-fitting}

The functional form that best captured the effect of diversity on production was the linear function (Akaike weight $=0.93$, Table 3, Fig. 6a). For consumption, the power function was the best model (Akaike weight $=1.00$, Table 3, Fig. 6b). Output from the models indicates that the coefficients for both production and consumption were positive $\left(\beta_{\text {prod }}=0.17\right.$ and (a)

Production

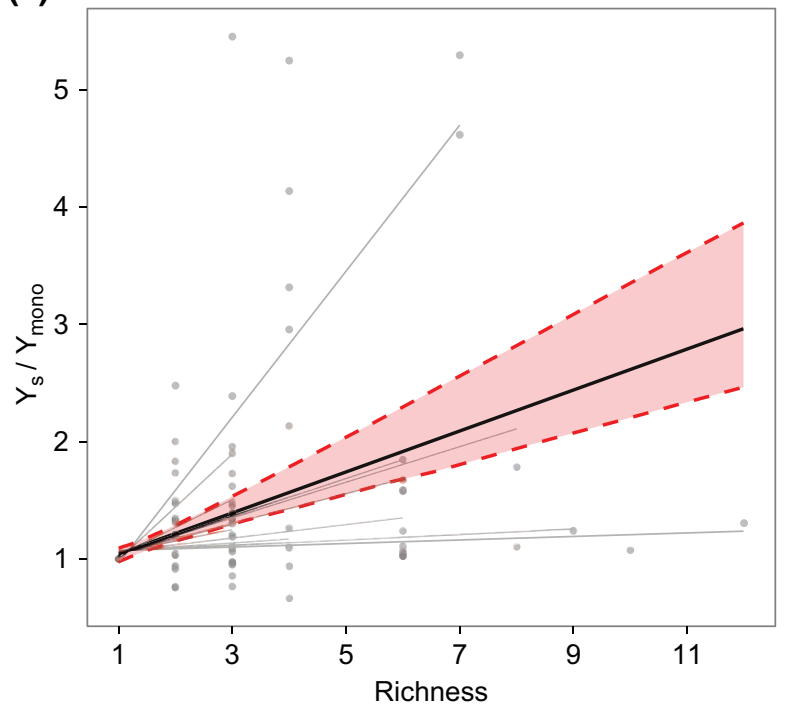

(b) Consumption

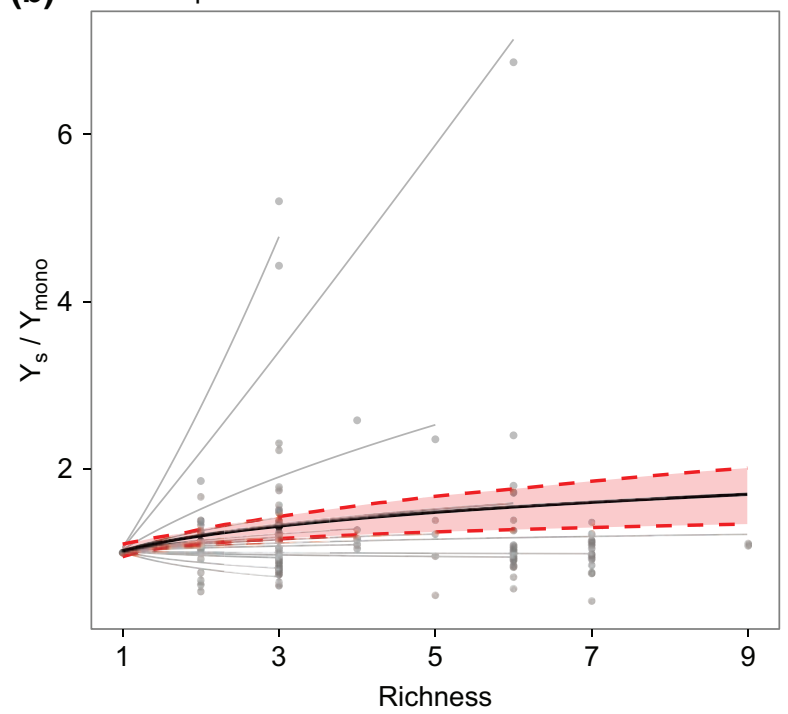

Figure 6. The curve-fits for the function categories (a) production and (b) consumption with 999 bootstrapped models. 95\% bootstrapped confidence interval shown by the red dashed lines.

$\left.\beta_{\text {cons }}=0.23\right)$ and different from zero $(p=0.024$ and $p=0.033$ respectively). For biogeochemical fluxes there was nearly equivalent support for all forms, likely driven by the relative lack of studies compared to production and consumption, as opposed to any idiosyncratic response in nature (Table 3).

\section{Discussion}

\section{What's known?}

Our results provide the most comprehensive quantitative synthesis of marine biodiversity-ecosystem function studies to date. We found that: 1) the level of functioning achieved within species-rich assemblages was generally greater than the average of the component species in monoculture; 2) species-rich assemblages tended to have lower or similar levels of functioning compared to the species with the most 
extreme monoculture; 3) the effects of species richness on biogeochemical fluxes, which to date have not been quantitatively summarised across studies, appeared to follow patterns similar to other well-studied ecosystem functions; 4) the shape of the richness-functioning relationship followed a linear function for production and a decelerating powerfunction for consumption. Our result that the most speciesrich polycultures tend to produce more biomass, consume more resources, and have higher biogeochemical fluxes than the average monoculture (Fig. 3) matches the findings of previous meta-analyses (Balvanera et al. 2006, Cardinale et al. 2006, 2011, Stachowicz et al. 2007, Schmid et al. 2009, Godbold 2012), and thus suggests a high degree of generality in our understanding of the effects of changing species richness. Furthermore, we find the qualitative agreement between our marine meta-analysis and similar work in terrestrial systems to be striking; the relationship between diversity and ecosystem functioning as predicted by theory appears to be non-system specific.

We found that 'transgressive overyielding' (i.e. mixtures of species performing better than their most extreme single species in monoculture) was uncommon within species rich marine assemblages, consistent with previous general syntheses. Interestingly, our marine results in fact showed lower levels of production and consumption on average than their most extreme single species. This is consistent with functions analysed by previous synthesis of primary producer experiments (Cardinale et al. 2011). It also resonates well with the findings in many individual studies that the exact composition of species is just as important, or even more important, than species richness per se (Huston and McBride 2002, Bruno et al. 2005, Gustafsson and Boström 2009). The extent to which composition or richness matters most for ecosystem functioning remains to be synthesised.

Our findings might suggest that the focal function would not be compromised by species losses if the best-performing species could be conserved, and further, that management for the single 'best' species, under perfect knowledge, could increase single target functions. It is plausible that increasing richness may impose 'costs' to certain ecological functions, such as when competition or other forms of antagonism reduce the performance of highly functional species when they interact with other species in polyculture. The results suggest that we could, in fact, conserve ecosystem functioning with single species if the following assumptions hold. First, that we have perfect knowledge of the functional characteristics of each species that allow selection of the 'best' performing one. Second, that the single chosen species will remain the best performer through inevitable spatial and temporal changes in the environment. Third, though not an assumption per se, that choosing the single species is optimal also for the other functions we may be interested in maximizing. Multiple studies now show that the best performing species for one function is not necessarily the best performing species for all functions (Gamfeldt et al. 2008, Zavaleta et al. 2010, Byrnes et al. 2014). It should also be noted that the equal replication of each species in monoculture, a standard experimental design choice, may be biased towards finding extreme values in single-species treatments, thereby biasing against finding a consistent positive effect of $\mathrm{LR}_{\text {ext }}$ (Schmid et al. 2008). However, there has not yet been a satisfactory method for dealing with such biases presented in the literature.

Bottom-up effects of changes in species richness (effects of primary producers on herbivores) have previously been shown to differ from the top-down effects of changes in species richness (Cardinale et al. 2011). We found no such differences (Supplementary material Appendix 3 Fig. A1), but note that our data set only included two experiments that studied bottom-up effects. We thus had little power for this comparison. Responses to changes in species richness have also been shown to differ between state and rate variables (Schmid et al. 2009). We found only one such discrepancy, which was for biogeochemical fluxes for $\mathrm{LR}_{\text {net }}$. One explanation for the only subtle differences might be that many of the rates included in our data are strongly related to the state variables measured. We cannot determine this from the data at hand, however. Future studies would benefit from explicitly comparing state and rate variables, e.g. by comparing the standing stock biomass of phytoplankton to the rate of phytoplankton production and respiration.

While the average effect of species richness on production $\left(\mathrm{LR}_{\text {net }}\right)$, consumption and biogeochemical fluxes is clear, we still see large variation in how it is manifested across trophic groups and functions. For example, there was no effect of primary producer richness on consumption, and no effect of carnivore richness on production (Fig. 4). Also, there was no effect of richness in pelagic or seagrass systems for consumption (Fig. 5). These results could represent real deviations from the general trend. However, since the trends in effects are mostly positive, another explanation is that they are an inevitable consequence of the lower number of studies available within some individual system-function or trophic group-function combinations. Indeed, all of the tests that did not show richness effects suffered from relatively small sample sizes (Fig. 4, 5). Thus, further investigations in these systems and trophic groups may shed light on this phenomenon.

Comparing the effect sizes for $\mathrm{LR}_{\text {net }}$ found in our study with those in previous meta-analyses of marine experiments (Table 4) indicates slightly weaker effects of changes in primary producer richness for the experiments included in our analysis. On the other hand, the effect of changes in carnivore richness on consumption is larger than for any other response category previously analysed - a finding consistent with a recent meta-analysis of carnivore richness effects across ecosystems (Griffin et al. 2013). On average, the effect sizes in all four meta-analyses are roughly of the same magnitude.

Predicting the consequences of changes in species richness requires an understanding of the form of the richnessfunctioning relationship. For production and consumption, we were able to estimate the general form of this relationship (Fig. 6), although data limitations did not allow similarly robust estimations for biogeochemical fluxes (Table 3). Previous analyses have found broad support for saturating relationships between richness and functioning (Cardinale et al. 2006, 2011). This form is generally consistent with the decelerating relationship observed for functions related to consumption (Fig. 6b).

However, our finding that production responds linearly to changes in species richness is a departure from previous 
Table 4. Comparing the effect sizes (ES) in this study with those in previous meta-analyses: Cardinale et al. 2006 (C2006), Worm et al. 2006 (W2006), and Cardinale et al. 2011 (C2011). Effect sizes are for net log response ratios $\left(\mathrm{LR}_{\mathrm{net}}\right) \pm 95 \%$ confidence intervals. The number of experiments included in each meta-analysis is listed as subscript. PP = primary producers. Note that the term 'production' encompasses both standing stock and rates in G 2014, whereas it infers only standing stock in the other analyses.

\begin{tabular}{|c|c|c|c|c|}
\hline Category & $\begin{array}{c}\mathrm{C} 2006 \\
\mathrm{LR}_{\text {net }}\end{array}$ & $\begin{array}{c}\text { W2006 } \\
\text { LR }_{\text {net }}\end{array}$ & $\begin{array}{l}\text { C2011 } \\
\text { LR }_{\text {net }}\end{array}$ & $\begin{array}{l}\mathrm{G} 2014 \\
\mathrm{LR}_{\text {net }}\end{array}$ \\
\hline Standing stock* & $0.37 \pm 0.17_{34}$ & & & \\
\hline Resource depletion* & $0.37 \pm 0.17_{38}$ & & & \\
\hline $\mathrm{PP}$, production & & $0.58 \pm 0.15_{3}$ & $\begin{array}{l}0.42 \pm 0.15_{53^{ \pm}} \\
0.57 \pm 0.01_{2}^{\$}\end{array}$ & $0.33 \pm 0.19_{31}$ \\
\hline $\mathrm{PP}$, resource use & & $0.18 \pm 0.06_{5}$ & & $-0.07 \pm 0.11_{23}{ }^{\mathrm{ns}}$ \\
\hline Consumers, production & & $0.57 \pm 0.18_{6}$ & & $0.49 \pm 0.23_{32}$ \\
\hline Consumers, resource use & & $0.32 \pm 0.19_{5}$ & & $0.32 \pm 0.14_{46}$ \\
\hline Carnivores, production & & & & $0.25 \pm 0.51_{4}{ }^{\mathrm{ns}}$ \\
\hline Carnivores, resource use & & & & $0.90 \pm 0.52_{12}$ \\
\hline
\end{tabular}

*the effect sizes from Cardinale et al. (2006) are for aquatic systems in general, and include both marine and freshwater systems, and are not split by trophic groups

fmarine coastal systems

$\$$ estuarine systems

${ }^{n s}$ Confidence intervals overlapping zero

findings. We tentatively suggest that this could be the result of the generally low number of species in the studies that measured production (median $=4$, range $=3-12$ ), which could limit the potential for increasingly overlapping niches to saturate the richness-production relationship. In other words, the linear relationship could represent the initial linear rise in production at relatively low species richness levels present in a saturating relationship. On the other hand, we were able to identify a non-linear power relationship for consumption with a lower median (3) and a smaller range (3-9) of richness. Nonetheless, the small number of data points on the $\mathrm{x}$-axis for each individual experiment is a serious limitation of our data set, and all conclusions based on the curve-fitting results should be interpreted with caution.

It should also be noted that comparisons to previous syntheses may be biased by the less sophisticated 'vote-counting' approach employed in earlier efforts (Cardinale et al. 2006, 2011). This approach has a lower statistical power to detect differences in the functional form, and thus power, paradoxically, decreases as more studies are added (Hedges and Olkin 1980). More importantly, the chance that two studies which have identical underlying functional forms will agree based on comparing significance tests (where $\alpha=0.05$ ) is only $\sim 90 \%$ (Gurevitch and Hedges 1999). The relatively high error rate may make it difficult to distinguish between functional forms that are relatively similar (e.g. logarithmic and saturating) but have different implications for functioning. Our AIC-based mixed model approach utilizes the entirety of the dataset and thus is a more powerful and rigorous approach to understanding the functional form of the BEF relationship. It should be noted, however, that the dataset is still limited by the number and breadth of studies that have already been conducted, and thus we again urge caution in interpreting these results.

\section{Limitations of the experiments performed to date}

There are numerous characteristics of the experimental studies included in our analysis that restrict our ability to extrapolate the results to nature. First, most studies have been short in duration and small in spatial scale (but see Stachowicz et al. 2008b) and have largely been performed in highly controlled and homogeneous environments, e.g. plastic or glass containers. Previous analyses have shown that the effect of species richness often increases with time (Cardinale et al. 2007, Stachowicz et al. 2008b, Reich et al. 2012) and environmental heterogeneity can influence the diversity-function relationship (Raffaelli 2006, Dyson et al. 2007, Griffin et al. 2009a; but see Weis et al. 2008, Gamfeldt and Hillebrand 2011). Our current knowledge about the role of temporal/spatial heterogeneity in affecting the biodiversity-functioning relationship is limited.

Second, the range of species diversity manipulated in the experiments to date. Given the differences in our curve fitting versus previous studies (Cardinale et al. 2006, 2011), we suggest that marine studies need to increase this range whenever possible in order to facilitate the cross-comparability of our results to those of other systems.

Third, most studies have been assembly experiments in which communities have been constructed by putting species together. More realistic inference may be gained from experiments in which species are removed from natural communities in the field (Diaz et al. 2003). There are only a few published removal experiments in marine systems, and these reveal effects of species richness that are equal to, or stronger than, the effects observed in the average lab assembly experiment (O'Connor and Crowe 2005, Maggi et al. 2009, Walker and Thompson 2010, Crowe et al. 2011, Davies et al. 2011). Removal experiments will be key for furthering our understanding of the role of biodiversity for functioning and complementing insights from the large number of assembly experiments performed to date. Removal experiments are also important for testing the compensatory ability of remaining species - a key assumption of the substitutive design used in most assembly experiments.

Fourth, experiments have focused on single functions, but simultaneously considering multiple functions may affect the importance of biodiversity, either positively or negatively 
(Byrnes et al. 2014, Hensel and Silliman 2013). Marine environments provide numerous services, including food production, waste assimilation, shoreline protection, climate regulation, and recreation (MEA 2005) and understanding how diversity contributes to the simultaneous maintenance of the functions underlying these services is key to ensuring their effective conservation and management.

Fifth, the vast majority of studies have used a replacement series design in which the density (or other choice of measured unit) of the focal organisms is held constant across richness levels (Jolliffe 2000). This was the design of all the experiments included in our meta-analysis. By holding total density constant, the replacement design confounds changes in species richness with changes in density of component species. Studies that have explicitly studied the interactive effects of changes in number of species with changes in density indicate that density-dependent effects may be common (Underwood 1978, Benedetti-Cecchi 2004, O'Connor and Crowe 2005, Griffin et al. 2008, Byrnes and Stachowicz 2009a, Maggi et al. 2009, 2011). The absence of positive mean values of $\mathrm{LR}_{\text {ext }}$ in our analyses could potentially be a consequence of reduced density of component species with increasing levels of richness. A replacement series design may be especially problematic in systems where a single species drives most of the functioning, since reducing the density of such species in higher diversity treatments should lead to a decrease in ecosystem functioning independently of species richness. The fact that the $\mathrm{LR}_{\mathrm{ext}}$ metric is often close to zero or negative, suggests that complementary and density-dependent effects may operate in opposite directions, but often with similar magnitude. One should note, however, that the choice of holding density constant across richness levels is less of an issue in studies that run long enough to allow population dynamics to occur.

Finally, marine biodiversity experiments have largely focused on species richness as a potential driver of functioning, while overlooking other aspects of biodiversity. Richness may fail to capture the degree of functional redundancy among species within an assemblage. Moving forward, it will be necessary to integrate functional traits and/or evolutionary differences (Griffin et al. 2009b, 2013, Best et al. 2013, Cadotte 2013) in investigating the relationship between diversity and functioning. Marine and terrestrial realms differ in terms of their phylogenetic diversity at higher levels. For example, 15 phyla are endemic to marine environments (Ray and Grassle 1991), and the primary producers in the ocean belong to several kingdoms whereas they are mainly from the Plantae kingdom on land (Guiry and Guiry 2013). A formal comparison of the relative importance of phylogenetic diversity for functioning between the two realms has yet to be performed.

Given the limited spatial scale of studies to date, and the resulting mismatch between our understanding of marine biodiversity-functioning relationships and the scales pertinent to management decisions, elucidating effects of diversity at larger scales is a key research frontier. Observational (i.e. correlational) studies provide one way forward because they do not require logistically-challenging manipulations (Emmerson and Raffaelli 2000), allowing the description of diversity-function relationships at scales of entire sites and regions (Godbold and Solan 2009, Mora et al. 2011). It may be important to consider that observational studies across spatial environmental gradients assess the effects of variation in diversity resulting from a species sorting process at the scale of local communities; they do not necessarily address the effect of losing species from the entire regional species pool (as simulated by small-scale biodiversity experiments such as assessed here). Only the latter scenario would limit the number and type of species available for sorting at the local community scale. While diversity and function may be linked under both scenarios, the mechanisms, diversityfunction relationships and management implications could vary widely. Furthermore, it is important to keep in mind in this context that an observed correlation does not necessarily equal causation between diversity and functioning. Finally, while observational studies can provide an illusion of being large-scale by spreading replicated sampling over large areas, in many cases the individual sampling units are small (e.g. 1 $\mathrm{m}^{-2}$ benthic grabs, or quadrats on the rocky shore) and may have questionable relevance to truly scaling-up our understanding of diversity-function linkages.

\section{What's next?}

Our results identify several key gaps in the field of marine biodiversity-ecosystem function research. First, while a few marine studies have explicitly measured biogeochemical fluxes, they are few in number relative to those that measure production and consumption, and have been confined to a single system. Given the long history of ecosystem ecology and biogeochemistry in marine biology and oceanography, marine biologists are uniquely poised to have a large contribution to this area of biodiversity-ecosystem functioning research.

Second, while meta-analyses and experiments show that the effects of changes in species richness are on par with the effects of other drivers of ecosystem change (Hooper et al. 2012, Tilman et al. 2012), we know little about the interactive effects of species richness and environmental factors, especially in marine systems (but see e.g. Blake and Duffy 2010, Eklöf et al. 2012, Godbold 2012). Furthermore, while we know that indirect effects can just as strongly influence functioning as direct effects (Wootton 2002, Alsterberg et al. 2013, Eisenhauer et al. 2013), indirect and interactive effects of changes in diversity and other factors must be explored further. As an example, acidification may have a direct and positive effect on primary production through increasing levels of $\mathrm{CO}_{2}$. But if acidification also decreases biodiversity, it may indirectly negatively affect primary production. The net outcome may be difficult to predict and more research is needed in this area.

Third, while local biodiversity can change and even increase due to invasive species (Sax and Gaines 2003, Byrnes et al. 2007), we know little about the effects of increases in richness in any system (but see Byrnes and Stachowicz 2009b, Karlson et al. 2011). Coastal and estuarine systems are particularly vulnerable to invasive species (Cohen and Carlton 1998), and thus represent ideal communities with which to explore this question.

Fourth, we highlight a need to increase our knowledge of marine biodiversity-ecosystem functioning relationships in salt marsh and pelagic habitats. Both were underrepresented in our sample, and as such their results were less conclusive (although 
we note that several important studies in these systems, such as Lee et al. 1985, Finke and Denno 2005, were excluded because they did not meet our criteria for inclusion).

Fifth, and as discussed above, future studies should explicitly consider manipulations of species density, such as combination additive-replacement designs or response surface designs, to disentangle density-dependent population processes and diversity effects. Density-dependent processes are pervasive ecological forces that shape natural communities. Biodiversity-ecosystem functioning experiments could prove more relevant for environmental management and conservation if they can inform on both the consequences of species loss and on the effects of reducing the population size of the most efficient species for a focal ecosystem process or service.

Last, while marine research has often led the way in the study of predation within the context of biodiversityecosystem functioning research, we still have only a relative handful of studies - and mostly in mesocosms - addressing the functional consequences of diversity within guilds of carnivorous predators. Again, research into the effects of predation has been a strength of marine ecology in the past (Paine 1969, Menge 1972, Wootton 1994). Given the importance of predation in marine systems, we suggest that marine research could break further ground in an appreciation of how changes in predator diversity can affect ecosystem functions.

While prey diversity generally increases standing stock biomass and production at higher trophic levels (Lefcheck et al. 2013), our marine-focused data set included only four experiments (Lee et al. 1991, Dam and Lopes 2003, Gamfeldt et al. 2005, Gustafsson and Boström 2009). Furthermore, our analyses did not consider trophic cascades, of which there are many prominent examples in the marine realm (Estes et al. 1998, Eriksson et al. 2009, Hughes et al. 2013). The few marine studies that have manipulated species richness and looked at the effects at two trophic levels down have found highly variable effects, ranging from weak to strong (Bruno and O'Connor 2005, Byrnes et al. 2006, Douglass et al. 2008). Several factors influence how the effects of predator diversity cascade down the food web, including the prevalence of omnivory, intra-guild interference and predation, as well as non-consumptive effects of predators on prey traits (reviewed by Preisser et al. 2005, Duffy et al. 2007, Bruno and Cardinale 2008). Further studies are necessary if we are to better understand how and when the diversity within and across trophic levels interacts to mediate trophic cascades.

The current literature on marine species richness and ecosystem functioning has a clear message: losing species will cause general reductions in ecosystem functions on average (see also Stachowicz et al. 2007, Worm et al. 2006). However, compared to the biodiversity-functioning field as a whole, the sample size for particular marine systems and function categories is low. At the same time, complementing the current literature with additional similar simplified experiments in the same systems will probably do little to change the overall picture presented in Fig. 3. What is now sorely needed is a new generation of experiments that target how spatial scale and heterogeneity, realistic local extinction scenarios, functional and phylogenetic composition, and other aspects of environmental change (especially temperature, acidification and pollution) influence the relationship between different dimensions of biodiversity and ecosystem functioning, and under natural conditions across spatial and temporal scales (Naeem et al. 2009b, Tomimatsu et al. 2013). Unique opportunities for testing the potential importance of diversity in influencing ecosystem processes may arise in the growing number of restoration projects in marine systems (see Doherty and Zedler 2014 for a case study in salt marshes). We also need to explicitly link functions in these experiments to ecosystem services (Cardinale et al. 2012, Balvanera et al. 2014). Only by expanding the scope and relevance of future experiments can we gain a more thorough understanding of the consequences of changes in marine biodiversity.

Acknowledgements - This work is part of the NCEAS working group 'Biodiversity and the functioning of ecosystems: translating results from model experiments into functional reality'. Support for NCEAS comes from Univ. of California Santa Barbara and the National Science Foundation. Mary O'Connor and Lisandro Benedetti-Cecchi provided valuable feedback on earlier drafts. LG was supported by grant 621-2009-5457 from the Swedish Research Council VR. JED had support from NSF OCE-1031061; BJC had support from NSF DEB-1046121.

\section{References}

Alsterberg, C. et al. 2013. Consumers mediate the effects of experimental ocean acidification and warming on primary producers. - Proc. Natl Acad. Sci. USA 110: 8603-8608.

Balvanera, P. et al. 2006. Quantifying the evidence for biodiversity effects on ecosystem functioning and services. - Ecol. Lett. 9: 1146-1156.

Balvanera, P. et al. 2014. Linking biodiversity and ecosystem services: current uncertainties and the necessary next steps. - BioScience 64: 49-57.

Barbier, E. B. et al. 2010. The value of estuarine and coastal ecosystem services. - Ecol. Monogr. 81: 169-193.

Beaugrand, G. et al. 2010. Marine biodiversity, ecosystem functioning, and carbon cycles. - Proc. Natl Acad. Sci. USA 107: 10120-10124.

Benedetti-Cecchi, L. 2004. Increasing accuracy of causal inference in experimental analyses of biodiversity. - Funct. Ecol. 18: 761-768.

Benedetti-Cecchi, L. 2006. Understanding the consequences of changing biodiversity on rocky shores: how much have we learned from past experiments? - J. Exp. Mar. Biol. Ecol. 338: 193-215.

Best, R. J. et al. 2013. Trait vs phylogenetic diversity as predictors of competition and community composition in herbivorous marine amphipods. - Ecol. Lett. 16: 72-80.

Blake, R. E. and Duffy, J. E. 2010. Grazer diversity affects resistance to multiple stressors in an experimental seagrass ecosystem. - Oikos 119: 1625-1635.

Boyer, K. E. et al. 2009. Biodiversity effects on productivity and stability of marine macroalgal communities: the role of environmental context. - Oikos 118: 1062-1072.

Bracken, M. E. S. and Stachowicz, J. J. 2006. Seaweed diversity enhances nitrogen uptake via complementary use of nitrate and ammonium. - Ecology 87: 2397-2403.

Bracken, M. E. S. and Low, N. H. N. 2012. Realistic losses of rare species disproportionately impact higher trophic levels. - Ecol. Lett. 15: 461-467. 
Bracken, M. E. S. et al. 2008. Functional consequences of realistic biodiversity changes in a marine ecosystem. - Proc. Natl Acad. Sci. USA 105: 924-928.

Bruno, J. F. and O'Connor, M. I. 2005. Cascading effects of predator diversity and omnivory in a marine food web. - Ecol. Lett. 8: 1048-1056.

Bruno, J. F. and Cardinale, B. J. 2008. Cascading effects of predator richness. - Front. Ecol. Environ. 6: 539-546.

Bruno, J. F. et al. 2005. Effects of macroalgal species identity and richness on primary production in benthic marine communities. - Ecol. Lett. 8: 1165-1174.

Bruno, J. F. et al. 2006. Partitioning the effects of algal species identity and richness on benthic marine primary production. - Oikos 115: 170-178.

Bruno, J. F. et al. 2008. Relative and interactive effects of plant and grazer richness in a benthic marine community. - Ecology 89: 2518-2528.

Burnham, K. P. and Anderson, D. R. 2002. Model selection and multimodel inference. - Springer.

Burrows, M. T. et al. 2011. The pace of shifting climate in marine and terrestrial ecosystems. - Science 334: 652-655.

Byrnes, J. E. and Stachowicz, J. J. 2009a. The consequences of consumer diversity loss: different answers from different experimental designs. - Ecology 90: 2879-2888.

Byrnes, J. E. and Stachowicz, J. J. 2009b. Short and long term consequences of increases in exotic species richness on water filtration by marine invertebrates. - Ecol. Lett. 12: 830-841.

Byrnes, J. et al. 2006. Predator diversity strengthens trophic cascades in kelp forests by modifying herbivore behaviour. - Ecol. Lett. 9: 61-71.

Byrnes, J. E. et al. 2007. Invasions and extinctions reshape coastal marine food webs. - PLoS ONE 2: e295.

Byrnes, J. E. K. et al. 2014. Investigating the relationship between biodiversity and ecosystem multifunctionality: challenges and solutions. - Meth. Ecol. Evol. 5: 111-124.

Cadotte, M. W. 2013. Experimental evidence that evolutionarily diverse assemblages result in higher productivity. - Proc. Natl Acad. Sci. USA 110: 8996-9000.

Callaway, J. C. et al. 2003. Species-rich plantings increase biomass and nitrogen accumulation in a wetland restoration experiment. - Ecol. Appl. 13: 1626-1639.

Cardinale, B. J. et al. 2006. Effects of biodiversity on the functioning of trophic groups and ecosystems. - Nature 443: 989-992.

Cardinale, B. J. et al. 2007. Impacts of plant diversity on biomass production increase through time because of species complementarity. - Proc. Natl Acad. Sci. USA 104: 18123-18128.

Cardinale, B. J. et al. 2009. Effects of biodiversity on the functioning of ecosystems: a summary of 164 experimental manipulations of species richness. - Ecology 90: 854-854.

Cardinale, B. J. et al. 2011. The functional role of producer diversity in ecosystems. - Am. J. Bot. 98: 572-592.

Cardinale, B. J. et al. 2012. Biodiversity loss and its impact on humanity. - Nature 486: 59-67.

Cohen, A. N. and Carlton, J. T. 1998. Accelerating invasion rate in a highly invaded estuary. - Science 279: 555-558.

Crowe, T. P. et al. 2011. Interactive effects of losing key grazers and ecosystem engineers vary with environmental context. - Mar. Ecol. Prog. Ser. 430: 223-234.

Dam, H. G. and Lopes, R. M. 2003. Omnivory in the calanoid copepod Temora longicornis: feeding, egg production and egg, hatching rates. - J. Exp. Mar. Biol. Ecol. 292: 119-137.

Davies, T. W. et al. 2011. Dominance, biomass and extinction resistance determine the consequences of biodiversity loss for multiple coastal ecosystem processes. - PLoS ONE 6(12): e28362.

Diaz, S. et al. 2003. Functional diversity revealed by removal experiments. - Trends Ecol. Evol. 18: 140-146.

Doherty, J. M. and Zedler, J. B. 2014. Dominant graminoids support restoration of productivity but not diversity in urban wetlands. - Ecol. Eng. 65: 101-111.
Doney, S. C. et al. 2012. Climate change impacts on marine ecosystems. - In: Carlson, C. A. and Giovannoni, S. J. (eds), Annual review of marine science, Vol. 4. Annual reviews, pp. 11-37.

Douglass, J. G. et al. 2008. Herbivore and predator diversity interactively affect ecosystem properties in an experimental marine community. - Ecol. Lett. 11: 598-608.

Duffy, J. E. 2002. Biodiversity and ecosystem function: the consumer connection. - Oikos 99: 201-219.

Duffy, J. E. et al. 2001. Grazer diversity, functional redundancy, and productivity in seagrass beds: an experimental test. - Ecology 82: 2417-2434.

Duffy, J. E. et al. 2003. Grazer diversity effects on ecosystem functioning in seagrass beds. - Ecol. Lett. 6: 637-645.

Duffy, J. E. et al. 2005. Ecosystem consequences of diversity depend on food chain length in estuarine vegetation. - Ecol. Lett. 8: 301-309.

Duffy, J. E. et al. 2007. The functional role of biodiversity in ecosystems: incorporating trophic complexity. - Ecol. Lett. 10: 522-538.

Dulvy, N. K. et al. 2003. Extinction vulnerability in marine populations. - Fish Fish. 4: 25-64.

Dyson, K. E. et al. 2007. Influence of macrofaunal assemblages and environmental heterogeneity on microphytobenthic production in experimental systems. - Proc. R. Soc. B 274: 2547-2554.

Eisenhauer, N. et al. 2013. Plant diversity effects on soil food webs are stronger than those of elevated $\mathrm{CO}_{2}$ and $\mathrm{N}$ deposition in a long-term grassland experiment. - Proc. Natl Acad. Sci. USA 110: 6889-6894.

Eklöf, J. S. et al. 2012. Experimental climate change weakens the insurance effect of biodiversity. - Ecol. Lett. 15: 864-872.

Emmerson, M. and Raffaelli, D. 2000. Detecting the effects of diversity on measures of ecosystem function: experimental design, null models and empirical observations. - Oikos 91: 195-203.

Emmerson, M. and Huxham, M. 2002. How can marine ecology contribute to the biodiversity-ecosystem functioning debate? - In: Loreau, M. et al. (eds), Biodiversity and ecosystem functioning synthesis and perspectives. Oxford Univ. Press, pp. 139-146.

Emmerson, M. et al. 2001. Consistent patterns and the idiosyncratic effects of biodiversity in marine ecosystems. - Nature 411: 73-77.

Ericson, J. et al. 2009. Are there direct and cascading effects of changes in grazer and predator species richness in a model system with heterogeneously distributed resources? - Mar. Biodiv. 39: 71-81.

Eriksson, B. K. et al. 2009. Declines in predatory fish promote bloom-forming macroalgae. - Ecol. Appl. 19: 1975-1988.

Estes, J. A. et al. 1998. Killer whale predation on sea otters linking oceanic and nearshore ecosystems. - Science 282: 473-476.

Finke, D. L. and Denno, R. F. 2005. Predator diversity and the functioning of ecosystems: the role of intraguild predation in dampening trophic cascades. - Ecol. Lett. 8: 1299-1306.

Foster, G. G. et al. 1999. Effect of diet on growth rate and reproductive fitness of Turbo sarmaticus (Mollusca : Vetigastropoda: Turbinidae). - Mar. Biol. 134: 307-315.

France, K. E. and Duffy, J. E. 2006. Diversity and dispersal interactively affect predictability of ecosystem function. - Nature 441: 1139-1143.

Gamfeldt, L. and Hillebrand, H. 2008. Biodiversity effects on aquatic ecosystem functioning - maturation of a new paradigm. - Int. Rev. Hydrobiol. 93: 550-564.

Gamfeldt, L. and Hillebrand, H. 2011. Effects of total resources, resource ratios and species richness on algal productivity and evenness at both metacommunity and local scales. - PLoS ONE 6: e21972.

Gamfeldt, L. et al. 2005. Species richness changes across two trophic levels simultaneously affect prey and consumer biomass. - Ecol. Lett. 8: 696-703. 
Gamfeldt, L. et al. 2008. Multiple functions increase the importance of biodiversity for overall ecosystem functioning. - Ecology 89: 1223-1231.

Godbold, J. A. 2012. Effects of biodiversity-environment conditions on the interpretation of biodiversity-function relations. - In: Solan, M. et al. (eds), Marine biodiversity and ecosystem functioning: frameworks, methodologies, and integration. Oxford Univ. Press, pp. 101-114.

Godbold, J. A. and Solan, M. 2009. Relative importance of biodiversity and the abiotic environment in mediating an ecosystem process. - Mar. Ecol. Prog. Ser. 396: 273-282.

Godbold, J. A. et al. 2009. Consumer and resource diversity effects on marine macroalgal decomposition. - Oikos 118: 77-86.

Griffen, B. 2006. Detecting emergent effects of multiple predator species. - Oecologia 148: 702-709.

Griffin, J. N. and Silliman, B. R. 2011. Predator diversity stabilizes and strengthens trophic control of a keystone grazer. - Biol. Lett. 7: 79-82.

Griffin, J. et al. 2008. Predator diversity effects and ecosystem functioning: density modifies the effect of resource partitioning. - Ecology 89: 298-305.

Griffin, J. N. et al. 2009a. Spatial heterogeneity increases the importance of species richness for an ecosystem process. - Oikos 118: 1335-1342.

Griffin, J. N. et al. 2009b. Functional diversity predicts overyielding effect of species combination on primary productivity. - Oikos 118: 37-44.

Griffin, J. N. et al. 2010. Consumer effects on ecosystem functioning in rock pools: roles of species richness and composition. - Mar. Ecol. Prog. Ser. 420: 45-56.

Griffin, J. N. et al. 2013. Effects of predator richness on prey suppression: a meta-analysis. - Ecology 94: 2180-2187.

Guiry, M. D. and Guiry, G. M. 2013. AlgaeBase. World-wide electronic publication, Natl Univ. of Ireland, Galway. <www. algaebase.org >; accessed 5 September 2013.

Gurevitch, J. and Hedges, L. V. 1999. Statistical issues in ecological meta-analyses. - Ecology 80: 1142-1149.

Gustafsson, C. and Boström, C. 2009. Effects of plant species richness and composition on epifaunal colonization in brackish water angiosperm communities. - J. Exp. Mar. Biol. Ecol. 382: 8-17.

Halpern, B. S. et al. 2008. A global map of human impact on marine ecosystems. - Science 319: 948-952.

Hawkins, S. J. et al. 2009. Consequences of climate-driven biodiversity changes for ecosystem functioning of north European rocky shores. - Mar. Ecol. Prog. Ser. 396: 245-259.

Hedges, L. V. and Olkin, I. 1980. Vote-counting methods in research synthesis. - Psychol. Bull. 88: 359-369.

Hedges, L. V. et al. 1999. The meta-analysis of response ratios in experimental ecology. - Ecology 80: 1150-1156.

Hensel, M. J. S. and Silliman, B. R. 2013. Consumer diversity across kingdoms supports multiple functions in a coastal ecosystem. - Proc. Natl Acad. Sci. USA 110: 20621-20626.

Hillebrand, H. et al. 2009. Consumer diversity indirectly changes prey nutrient content. - Mar. Ecol. Prog. Ser. 380: 33-41.

Hoegh-Guldberg, O. and Bruno, J. F. 2010. The impact of climate change on the World's marine ecosystems. - Science 328: 1523-1528.

Hooper, D. U. et al. 2005. Effects of biodiversity on ecosystem functioning: a concensus of current knowledge. - Ecol. Monogr. 75: 3-35.

Hooper, D. U. et al. 2012. A global synthesis reveals biodiversity loss as a major driver of ecosystem change. - Nature 486: $105-108$.

Hughes, B. B. et al. 2013. Recovery of a top predator mediates negative eutrophic effects on seagrass. - Proc. Natl Acad. Sci. USA 110: 15313-15318.

Huston, M. A. and McBride, A. C. 2002. Evaluating the relative strengths of biotic versus abiotic controls on ecosystem processes. - In: Loreau, M. et al. (eds), Biodiversity and ecosystem functioning, synthesis and perspectives. Oxford Univ. Press, pp. 47-60.

Ieno, E. N. et al. 2006. How biodiversity affects ecosystem functioning: roles of infaunal species richness, identity and density in the marine benthos. - Mar. Ecol. Prog. Ser. 311: 263-271.

Ives, A. R. et al. 2005. A synthesis of subdisciplines: predator-prey interactions, and biodiversity and ecosystem functioning. - Ecol. Lett. 8: 102-116.

Jaschinski, S. et al. 2009. Grazer diversity effects in an eelgrassepiphyte-microphytobenthos system. - Oecologia 159: 607-615.

Jolliffe, P. A. 2000. The replacement series. - J. Ecol. 88: 371-385.

Jones, C. G. et al. 1994. Organisms as ecosystem engineers. - Oikos 69: 373-386.

Karlson, A. M. L. et al. 2010. Higher diversity of deposit-feeding macrofauna enhances phytodetritus processing. - Ecology 91: 1414-1423.

Karlson, A. M. L. et al. 2011. Polychaete invader enhances resource utilization in a species-poor system. - Oecologia 166: 1055-1065.

Lee, W. Y. et al. 1985. Feeding and reproductive performance of the harpacticoid Tisbe carolinensis (Copepoda, Crustacea) in 4 algal cultures. - Mar. Ecol. Prog. Ser. 24: 273-279.

Lee, J. J. et al. 1991. Nutritional and related experiments on laboratory maintenance of 3 species of symbiont-bearing, large foraminifera. - Mar. Biol. 109: 417-425.

Lefcheck, J. S. et al. 2012. Physiological effects of diet mixing on consumer fitness: a meta-analysis. - Ecology 94: 565-572.

Loreau, M. 1998. Biodiversity and ecosystem functioning: a mechanistic model. - Proc. Natl Acad. Sci. USA 95: 5632-5636.

Loreau, M. et al. 2001. Biodiversity and ecosystem functioning: current knowledge and future challenges. - Science 294: 804-808.

Maggi, E. et al. 2009. Effects of changes in number, identity and abundance of habitat-forming species on assemblages of rocky seashores. - Mar. Ecol. Prog. Ser. 381: 39-49.

Maggi, E. et al. 2011. Connell and Slatyer's models of succession in the biodiversity era. - Ecology 92: 1399-1406.

Matthiessen, B. et al. 2007. Effects of grazer richness and composition on algal biomass in a closed and open marine system. - Ecology 88: 178-187.

Menge, B. A. 1972. Competition for food between two intertidal starfish species and its effect on body size and feeding. - Ecology 53: 635-644.

Mermillod-Blondin, F. et al. 2005. Biodiversity of benthic invertebrates and organic matter processing in shallow marine sediments: an experimental study. - J. Exp. Mar. Biol. Ecol. 315: 187-209.

MEA 2005. Millennium Ecosystem Assessment. Ecosystems and human well-being: biodiversity synthesis. - Island Press.

Moore, T. N. and Fairweather, P. G. 2006. Decay of multiple species of seagrass detritus is dominated by species identity, with an important influence of mixing litters. - Oikos 114: 329-337.

Moorthi, S. I. et al. 2008. Consumer diversity enhances secondary production by complementarily effects in experimental ciliate assemblages. - Estuaries Coasts 31: 152-162.

Mora, C. et al. 2011. Global human footprint on the linkage between biodiversity and ecosystem functioning in reef fishes. - PLoS Biol. 9(4): e1000606.

Murray, M. M. and Marcus, N. H. 2002. Survival and diapause egg production of the copepod Centropages hamatus raised on dinoflagellate diets. - J. Exp. Mar. Biol. Ecol. 270: 39-56.

Naeem, S. et al. 1994. Declining biodiversity can alter the performance of ecosystems. - Nature 368: 734-737.

Naeem, S. et al. 2009a. Biodiversity, ecosystem functioning, and human wellbeing, an ecological and economic perspective. - Oxford Univ. Press.

Naeem, S. et al. 2009b. Introduction: the ecological and social implications of changing biodiversity. An overview of a decade 
of biodiversity and ecosystem functioning research. - In: Naeem, S. et al. (eds.), Biodiversity, ecosystem functioning and human wellbeing. Oxford Univ. Press, pp. 3-13.

Norling, K. et al. 2007. Importance of functional biodiversity and species-specific traits of benthic fauna for ecosystem functions in marine sediment. - Mar. Ecol. Prog. Ser. 332: 11-23.

O'Connor, N. E. and Crowe, T. P. 2005. Biodiversity loss and ecosystem functioning: distinguishing between number and identity of species. - Ecology 86: 1783-1796.

O'Connor, M. I. and Bruno, J. F. 2009. Predator richness has no effect in a diverse marine food web. - J. Anim. Ecol. 78: 732-740.

O'Connor, M. I. and Byrnes, J. E. K. 2013. Biodiversity and ecosystem function in marine ecosystems. - In: Bertness, M. D. et al. (eds), Marine community ecology and conservation. Sinauer.

O'Connor, N. E. et al. 2008. Simulated predator extinctions: predator identity affects survival and recruitment of oysters. - Ecology 89: 428-438.

Paine, R. T. 1969. The Pisaster-Tegula interaction: prey patches, predator food preference and intertidal community structure. - Ecology 50: 950-961.

Pinheiro, J. et al. 2013. nlme: linear and nonlinear mixed effects models.

Poore, A. G. B. et al. 2012. Global patterns in the impact of marine herbivores on benthic primary producers. - Ecol. Lett. 15: 912-922.

Preisser, E. L. et al. 2005. Scared to death? The effects of intimadtion and consumption in predator-prey interactions. - Ecology 86: 501-509.

Raffaelli, D. G. 2006. Biodiversity and ecosystem functioning: issues of scale and trophic complexity. - Mar. Ecol. Prog. Ser. 311: 285-294.

Raffaelli, D. et al. 2003. Biodiversity and ecosystem processes in shallow coastal waters: an experimental approach. - J. Sea Res. 49: 133-141.

Ray, G. C. and Grassle, J. F. 1991. Marin biologocal diversity. - Bioscience 41: 453-457.

Reich, P. B. et al. 2012. Impacts of biodiversity loss escalate through time as redundancy fades. - Science 336: 589-592.

Salo, T. et al. 2009. Effects of plant diversity on primary production and species interactions in brackish water angiosperm, communities. - Mar. Ecol. Prog. Ser. 396: 261-272.

Sax, D. F. and Gaines, S. D. 2003. Species diversity: from global decreases to local increases. - Trends Ecol. Evol. 18: 561-566.

Schmid, B. et al. 2008. Biodiversity effects and transgressive overyielding. - J. Plant Ecol. 1: 95-102.

Schmid, B. et al. 2009. Consequences of species loss for ecosystem functioning: meta-analyses of data from biodiversity experiments. - In: Naeem, S. et al. (eds), Biodiversity, ecosystem functioning, and human wellbeing: an ecological and economic perspective. Oxford Univ. Press.

Solan, M. et al. 2004. Extinction and ecosystem function in the marine benthos. - Science 306: 1177-1180.

Supplementary material (available online as Appendix oik.01549 at <www.oikosjournal.org/readers/appendix >). Appendix 1. R code for data handling, analyses, and figure plotting. Appendix 2. Data as .txt file. Appendix 3. Supplementary figures/results. Including Fig. A1 (comparing response variables when measured at the focal [within] trophic level or at adjacent [bottom-up and top-down] trophic levels; Fig. A2 (jacknife simulations of removing individual studies from the effect of producer richness on consumption); Fig. A3 (state vs rate variables); Fig. A4 (comparing experiments performed in the field, in mesocosms and in the lab).
Solan, M. et al. 2012. Marine biodiversity and ecosystem functioning: frameworks, methodologies, and integration. - Oxford Univ. Press.

Stachowicz, J. J. et al. 2007. Understanding the effects of marine biodiversity on communities and ecosystems. - Annu. Rev. Ecol. Evol. Syst. 38: 739-766.

Stachowicz, J. J. et al. 2008a. Complementarity in marine biodiversity manipulations: reconciling divergent evidence from field and mesocosm experiments. - Proc. Natl Acad. Sci. USA 105: 18842-18847.

Stachowicz, J. J. et al. 2008b. Diversity enhances cover and stability of seaweed assemblages: the importance of environmental heterogeneity and experimental duration. - Ecology 89: 3008-3019.

Thébault, E. and Loreau, M. 2003. Food-web constraints on biodiversity-ecosystem functioning relationships. - Proc. Natl Acad. Sci. USA 100: 14949-14954.

Tilman, D. and Downing, J. A. 1994. Biodiversity and stability in grasslands. - Nature 367: 363-365.

Tilman, D. et al. 1997. The influence of functional diversity and composition on ecosystem processes. - Science 277: 1300-1302.

Tilman, D. et al. 2012. Biodiversity impacts ecosystem productivity as much as resources, disturbance, or herbivory. - Proc. Natl Acad. Sci. USA 109: 10394-10397.

Tomimatsu, H. et al. 2013. FORUM: Sustaining ecosystem functions in a changing world: a call for an integrated approach. - J. Appl. Ecol. 50: 1124-1130.

Underwood, A. J. 1978. Experimental evaluation of competition between 3 species of intertidal prosobranch gastropods. Oecologia 33: 185-202.

Vanelslander, B. et al. 2009. Complementarity effects drive positive diversity effects on biomass production in experimental benthic diatom biofilms. - J. Ecol. 97: 1075-1082.

Walker, M. K. and Thompson, R. M. 2010. Consequences of realistic patterns of biodiversity loss: an experimental test from the intertidal zone. - Mar. Freshw. Res. 61: $1015-1022$.

Weis, J. J. et al. 2008. Effects of algal diversity on the production of biomass in homogeneous and heterogeneous nutrient environments: a microcosm experiment. - PLoS ONE 3: e2825.

Wootton, J. T. 1994. Prediciting direct and indirect - an integrated approach using experiments and path analysis. - Ecology 75: $151-165$.

Wootton, J. T. 2002. Indirect effects in complex ecosystems: recent progress and future challenges. - J. Sea Res. 48: $157-172$.

Worm, B. et al. 2006. Impacts of biodiversity loss on ocean ecosystem services. - Science 314: 787-790.

Zavaleta, E. S. et al. 2010. Sustaining multiple ecosystem functions in grassland communities requires higher biodiversity. - Proc. Natl Acad. Sci. USA 107: 1443-1446. 